\title{
Experiência estética infantil e a relação com obra de arte nos espaços artísticos
}

\author{
Children's aesthetic experience and the relationship work \\ of art in artistic spaces
}

\section{La experiencia estética infantil y la relación con la obra de arte en los espacios artísticos}

Fernanda Ferreira de Oliveira'

https://orcid.org/0000-0001-5390-1206

\begin{abstract}
Resumo: $O$ presente texto tem por objetivo apresentar uma reflexão sobre experiência estética na educação infantil, por meio do ato de garimpar e analisar a documentação pedagógica, que por sua vez carrega as minúcias e os indícios de experiências estéticas infantis, que são resultados de um projeto educativo de Ocupação de espaços públicos e culturais artísticos por crianças pequenas entre 4 e 6 anos na cidade de Piracicaba. As crianças participantes do referido projeto colaboraram no desenvolvimento da pesquisa de mestrado no qual é exposto o presente artigo. A discussão do direito à cidade e ocupação perpassa a ideia de formação estética como parte da formação integral de crianças pequenas. Walter Benjamin e Lev Vigotski foram considerados como aportes teóricos para embasar a construção conceitual da experiência estética infantil
\end{abstract}

Palavras-chave: Pesquisa. Educação infantil. Ocupação. Cidade. Arte.

\begin{abstract}
The present text aims to present a reflection on aesthetic experience in early childhood education, through the act of mining and analyzing the pedagogical documentation, which in turn carries the minutiae and evidence of children's aesthetic experiences, which are the results of an educational project of Occupation of public and cultural artistic spaces by young children between 4 and 6 years old in the city of Piracicaba. The children participating in this project collaborated in the development of the master's research in which the present article is exposed. The discussion of the right to the city and occupation permeates the idea that aesthetic formation is part of the integral formation of young children. Walter Benjamin and Lev Vigotski were considered as theoretical contributions to support the conceptual construction of children's aesthetic experience.
\end{abstract}

Keywords: Research. Child education. Occupation. City. Art.

Resumen: El presente texto ofrece una reflexión sobre la experiencia estética en la educación infantil, a través la revisión y análisis de la documentación pedagógica, que a su vez contiene los detalles y evidencias de las experiencias estéticas que resultaron de un proyecto educativo de ocupación de espacios artísticos públicos y culturales por parte de niños de entre 4 y 6 años en la ciudad de Piracicaba. Los niños participantes en este proyecto colaboraron en el desarrollo de la investigación de Maestría en la que se expone el presente trabajo. La discusión sobre el derecho a la ciudad y la ocupación de los espacios públicos impregna la idea de que la

\footnotetext{
' Doutoranda e Mestra em educação PPGE- UNIMEP. Professora de Educação Infantil. EMI Piracicaba. E-mail: nandaferreira4@hotmail.com
}

Olhar de professor, Ponta Grossa, v. 24, p. I-I8, e-17645.078, 2021.

Disponível em <https://revistas2.uepg.br/index.php/olhardeprofessor> 
formación estética es parte de la formación integral de los niños pequeños. Walter Benjamin y Lev Vigotski fueron considerados como contribuciones teóricas para apoyar la construcción conceptual de la experiencia estética de los niños.

Palabras clave: Investigación. Educación infantil. Ocupación. Ciudad. Arte.

\section{Introdução}

Prô! Vamos à cidade ver obras de arte! (João, 5 anos)

A discussão sobre experiência estética com a arte na educação infantil é um tema que vem crescendo e sendo valorizado nos diversos campos educacionais (pesquisa, fóruns, congressos e seminários), e nós professoras/pesquisadoras temos percebido, principalmente na perspectiva de compreender como possibilidade de experiência formativa para crianças pequenas. Contudo, não se trata de um processo de ensino sistematizado de conteúdos da arte, como é comum em outros níveis da educação básica, mas tem o propósito de estreitar a relação das crianças com a produção cultural humana, possibilitando o desenvolvimento da sensibilidade, da empatia, da criatividade, da percepção, da emoção, da imaginação e de seu conhecimento sobre o mundo (OLIVEIRA, 20I7).

Ainda que as discussões entre educação infantil, experiência estética e arte tenham sido afloradas no campo das políticas públicas educacionais, e especificamente a partir da publicização das Diretrizes Curriculares da educação Infantil (2013), ainda tem se tornado um grande desafio construir processos que resistem à visão higienista, cognitivista e assistencialista de atendimento à infância, que enfrentam experiências que banalizam e empobrecem a relação com a arte, como as famosas pastinhas ou a didatização e a psicologização da arte no chão da escola.

O presente texto salienta que outras coisas têm acontecido ao redor da valorização da experiência estética, como, a presença da diversidade, do direito ao espaço, da construção do pertencimento, do hibridismo, das diferenças, da mistura, do místico, do brincar e do jogo. E, a educação da pequena infância não está apartada dessa visão pela/na/com a arte e de uma estética que é múltipla.

É importante enfatizar que a Educação infantil é a primeira etapa da Educação Básica e tem como finalidade o desenvolvimento integral da criança de zero a seis anos de idade, em seus aspectos físico, afetivo, intelectual, linguístico, cultural, histórico e social, completando a ação da família e da comunidade (BRASIL, 20I3). Construir um compromisso com a educação integral da criança pequena implica em um olhar cuidadoso e de respeito a sua dimensão físico/corporal, mas também no aspecto cultural que implicam na formação do seu pensamento e do seu sentimento.

A especificidade desse nível de educação se constitui pela produção de uma pedagogia da escuta e do olhar em que as potencialidades das crianças pequenas são fomentadas a partir do que elas são e 
não por quem vão se tornar. É vê-las a partir da sua relação autêntica com a cultura e a história, é compreendê-las pela leitura inventiva que fazem do mundo, capazes de se apropriarem de forma talentosa do patrimônio simbólico e material da humanidade, com a construção de vínculos e de significados para com a vida, no âmbito individual e coletivo, e a experiência estética infantil é gerada a partir dessas concepções! Tais premissas estão presentes no conceito da pedagogia da infância que produz um diálogo com outros segmentos das ciências humanas, dos defendem a infância como uma construção social, contextualizada no tempo/espaço e na cultura, com isto não havendo uma infância universal, e sim de produção de diferentes infâncias, pois existem diferentes crianças. A criança é compreendida como agente da construção da sua identidade, autonomia e sabedoria (OLIVEIRA, 2017).

A arte nessa perspectiva oportuniza o contato com nossa dimensão humana de qualidade trágico/poético e finito/incompleto, que nos causa ao mesmo tempo estranhamento e entendimento acerca da experiência estética, como produção e constituição decorrente de processos históricos mobilizando sentidos. Esses pormenores, a respeito do que a arte pode mobilizar, são de grande importância para a pequena infância, tendo a experiência estética como processo que se dá nos encontros do eu e do outro na constituição humana e na dinâmica do processo cultural, uma vez que o outro que não sou eu, mas está em mim, se manifesta paradoxalmente como espelho e evoca nossos sentimentos, emoções e afetividades. Além do que, a relação possibilitada pela experiência estética entre as linguagens e as lógicas imaginativas e inventivas das crianças amplia e dá sentido novo ao mundo.

Este texto tem por objetivo refletir a constituição da experiência estética infantil no contexto da educação infantil pública, a partir de vivências de crianças pequenas de 4 à 6 anos envolvidas num projeto educativo que produz Ocupação de crianças pequenas em espaços públicos e culturais artísticos na cidade de Piracicaba.

O estudo trata de um recorte de uma pesquisa documental, em nível de mestrado², e tem como enfoque compreende de que modos às crianças pequenas de educação infantil se relacionam com a arte e os espaços artísticos, e como nesse processo a experiências estéticas formativas infantis se constituem. É uma pesquisa de aporte qualitativa, apoiado nos registros coletados resultantes dos processos vivenciados durante as ocupações. Tais documentações foram elaboradas pela professora que também se tornou pesquisadora deste estudo.

\footnotetext{
${ }^{2}$ Mestrado finalizado em 2017 sob orientação da Professora Doutora Maria Nazaré Cruz, a pesquisa passou pelo processo e foi aprovado pelo Comitê de Ética. Todas as imagens de crianças presentes no texto foram autorizadas por seus responsáveis.
}

Olhar de professor, Ponta Grossa, v. 24, p. I-18, e-17645.078, 2021.

Disponível em <https://revistas2.uepg.br/index.php/olhardeprofessor> 


\section{Relações entre experiência estética infantil, ocupação e direito à cidade}

O contexto cultural e histórico é marcador no processo de produção e mediação da arte. As obras de artísticas elaboradas a partir de sentidos estéticos é uma criação humana acarretada por valores humanos, construída por meio de conhecimentos técnicos, de processos criativos e expressivos. Nesse sentido, pensar a construção de uma relação da criança pequena frente à obra de arte é considerar a possibilidade da constituição como sujeito de direito, produtora de cultura, pertencente a uma classe social, a uma cidade, um bairro, uma comunidade, uma família, a uma escola. Neste sentido, frente a uma obra de arte a criança pequena não é neutra e muito menos indiferente, e ao tentar se apropriar dos significados das coisas da cultura, apoiando-se nos sentidos que o outro mais experiente atribui, e não faz isso de forma passiva, vai interagindo e atribuindo sentidos, conforme se apropriam e dominam a linguagem (CRUZ, 2007).

E ao falar dessa relação da criança e a arte, a experiência estética não está apartada dessa discussão já que historicamente arte e da estética, ainda que de forma pragmática, foram integradas para explicar a questão do belo na modernidade. Ou seja, a estética nesse momento da história estava sendo entendida como apartada do corpo/sentido colocando o cognitivo como superior ao corpo (EAGLETON, 1993).

Optou-se por abordar a perspectiva de experiência estética a partir de dois autores, que representam teorias que se acredita serem complementares em alguns aspectos, que são eles Walter Benjamin e Vigotski. Os dois estudiosos desenvolvem discussões sobre experiências da qual a base é materialista histórica dialética, em que o sujeito se apropria da cultura existente ao mesmo tempo em que produz algo novo, e este novo é a história (OLIVEIRA, 2017). A experiência estética quanto conceito pode ser entendida como estudo da formação estética do sujeito no campo do sensível e da subjetividade frente às impressões sofridas na realidade objetiva, ou seja, forjada na experiência prática em diálogo com a arte, a ciência e o cotidiano. É um estado ativo das pessoas, assim como a experiência do narrar, como o Narrador de Benjamin, como da imaginação fantástica em Vigotski.

Contudo, a pesquisa demonstrou que quando a relação arte e estética se aproximam da criança pequena, necessariamente o valor cognitivista da estética precisa ser revisto dando espaço para compreender a experiência estética infantil como categoria de estudo e de entendimento de um tipo de construção de experiência, que se relaciona com o processo sensoperceptivo, sensível, afetiva, emotivo e brincante.

A experiência estética infantil enquanto categoria é algo que tem sido desenvolvido, visto que no campo teórico em que ela possa estar inserida (filosofia, estética, infância, educação), é tratada muitas vezes com uma simples transposição da concepção da experiência estética clássica adulta para a criança (OLIVEIRA, 20I7). Entretanto, é possível encontrar alguns indícios relevantes quando nos 
deparamos com experiências concretas de crianças pequenas na vivência com a obra de arte em diversas situações e contextos. No caso dos espaços/tempos da educação infantil pública existem fatores que envolvem o entendimento social, cultural e afetivo das relações, pois, crianças pequenas, filhas e filhos de famílias pobres, de maioria negra, periférica necessitam de políticas públicas em diferentes segmentos e encontram na creche e na pré-escola o respeito e a garantia da dignidade humana, em que suas vozes ecoam nos diferentes contextos da educação e são vistas na sua integralidade e totalidade. Local que compreende as contribuições das pequenas e dos pequenos na construção da cultura e na formação individual e coletiva da sociedade. Nesse sentido, a educação estética não está fora dessa valorização na formação da pequena infância, por isso deve ser pensada de forma integral.

Quando se pensa uma educação infantil como educação integral está se baseando numa lógica acolhedora da participação da criança pequena no seu próprio desenvolvimento, que dialogue com todas as dimensões humanas físico, emocional, social, cultural, simbólico e afetivo. Compreender e conceber que a escola da infância compartilha da responsabilidade da educação e cuidado de crianças pequenas com a sociedade como um todo, assim como diz o provérbio nigeriano: "Para educar uma criança é preciso uma aldeia inteira".

Vislumbrar o território da escola e da cidade como espaços de conhecimento a serem apropriados pelas crianças pequenas é valorizá-los como co-responsáveis pela educação dessas meninas e meninos. As crianças pequenas quando estão fora do espaço privado (família) tem a oportunidade de se encantarem e aprenderem as lógicas e os arranjos que compõem esses lugares externos, que são repletos de provocações estéticas, como a arquitetura urbana com seus prédios, casas e ruas; as praças, parques e bosques; a composição da natureza e as construções; os espaços culturais, artísticos e monumentais. E a escola de educação infantil pode e deve organizar vivências fora do seu espaço, já que as crianças passam a maior parte do dia e da semana acolhidas nesse local, e criar possibilidades de aprender em outros espaços são experiências enriquecedoras.

O tema do direito à cidade e a cidade educadora não é uma discussão nova, se contarmos como o bom exemplo a cidade de Rosário na Argentina, que desde 1996 o governo visa políticas públicas para cidade, redesenhando a cidade de forma que possibilitasse práticas conscientes de relações entre as pessoas, e entre as pessoas e a cidade de maneira mais próxima, e também algo específico para pequena infância que integra transporte público e lazer, e oferecer aos mais vulneráveis como forma de igualdade de direitos.

Olhar de professor, Ponta Grossa, v. 24, p. I-18, e-17645.078, 202 I.

Disponível em <https://revistas2.uepg.br/index.php/olhardeprofessor> 
No Brasil essa discussão vem tomando formas potentes e realizáveis como o Prêmio Território ${ }^{3}$ que reconhece projetos que conectem escolas ao seu entorno e à cidade, bem como o Projeto Ocupa a Cidade ${ }^{4}$.

O campo de estudo da Geografia da Infância tem contribuído (LOPES e VASCONCELLOS, 2005) significativamente para o debate da emergência do tema sobre quais são os sentidos de infância em relação ao espaço geográfico, o como isto modifica de acordo com as mudanças sóciais, econômicas, religiosas e políticas. Tal reestruturação do espaço afeta a relação de conivência entre as pessoas, e quando se olha para crianças, quanto recorte etário, existem marcas de uma espacialidade seja ela privada ou pública de confinamentos desses pequenos corpos, pois no espaço da família (privado) é contido em casa e no público é retido dentro dos muros das escolas e colégios. Estes são aspectos equivocados do sentido de proteção e segurança, porque se confundem com o controle da liberdade de movimentos em espaços abertos.

A partir desta perspectiva, Stuart Aitken (2014) tem colaborado a pensar sobre o direito da criança à cidadania argumentando que os espaços da cidade são transformativos, na medida em que "práticas políticas, estéticas, econômicas, terapêuticas, sociais e culturais complexamente entrelaçadas" (p.676) se abrem para o público infantil. Aitken, apoiado em Henri Lefebvre, aponta que o direito da criança à cidade não é apenas uma questão material, mas o direito de se apropriar e construí história e cultura dentro do território, pois há lógicas coletivas que são constituídas exclusivamente nesses ambientes.

E ao olharmos de forma mais pontual para a pesquisa, em que analisa um projeto educativo de uma escola de educação infantil no interior de São Paulo, numa região periférica de Piracicaba, que ousou de uma forma bem original organizou imersões e ocupações de espaços por crianças pequenas e bebês a partir do ano de 2015. Essas ocupações aconteciam dentro da própria escola por meio de produção de espaços convidativos a exploração e experimentações, bem como a ocupação de espaços culturais e artísticos da cidade. Nota-se que para este último às ferramentas culturais artísticas se encontram majoritariamente no centro urbano da cidade, e para que as crianças envolvidas no projeto chegassem até a região central demandou logísticas e formas que preservasse a segurança das crianças para uma ótima realização do projeto.

A ocupação, vista pelo projeto educativo como uma prática de direito à cidade pelas crianças pequenas, de forma sistematizada nos espaços culturais e artísticos na cidade de Piracicaba foi uma novidade, mesmo que centrada em apenas uma escola de educação infantil, necessitou um

\footnotetext{
${ }^{3}$ https://www.institutotomieohtake.org.br/premios/territorios-educativos

4 https://portal.aprendiz.uol.com.br/2020/06//6/territorios-de-sao-paulo-se-mobilizam-para-o-festival-ocupacidade/
}

Olhar de professor, Ponta Grossa, v. 24, p. I-18, e-17645.078, 2021.

Disponível em <https://revistas2.uepg.br/index.php/olhardeprofessor> 
planejamento que envolvesse vários segmentos - secretarias municipais de educação, transporte, cultura, câmara dos vereadores e o SESC local.

Ao pensar grupo de crianças entre 4 e 6 anos, participantes do projeto, foi possível perceber, como essas produzem formas peculiares de ocuparem e estabelecerem relações com os espaços, com os objetos dos espaços, com as pessoas que circulam e cuidam desses locais e principalmente com a obra de arte. Essas posturas infantis, frente a esses espaços e objetos, são constituídas por brincadeiras, corporalidade, imaginação e invenções.

A novidade de estarem em um lugar diferente da casa e do próprio espaço da educação infantil era motivo de entusiasmo e euforia por parte das crianças pequenas, pois tudo aquilo era incomum as suas experiências estéticas e miméticas, eram novas sensações. E quando as ocupações eram realizadas especificamente nos espaços culturais artísticos, tal situação aguçava as crianças de forma muito particular, pois ao se depararem com as lógicas peculiares desses espaços as experiências sensíveis foram despertadas de outras formas, pois são espaços que possuem especificidades provocativas.

Esse projeto, ainda que de forma pontual, revelou que o entendimento do direito das crianças pequenas à cidade e seus diferentes espaços propiciam maneiras com que elas possam se apropriar de novas realidades por meio da ocupação. Viver a cidade se constitui como elemento fundamental do desenvolvimento integral das crianças. Sair da "caixa" é oportunizar surpresas, é poder correr, conhecer pessoas, descobrir a natureza e a cultura, sentir texturas e cheiros, admirar as cores, aprender nomes de ruas, imaginar histórias! É possível conhecer o mundo e também as regras da sociedade por meio do espaço.

A sabedoria se aprende por meio da vivência pessoal e não apenas pela experiência do outro, que conta sua experiência, mesmo que utilizem de diferentes suportes como imagens, fotografias, vídeos, histórias, nada se compara experiência social objetiva e coletiva presente na cidade.

Entretanto, o projeto educativo revelou obstáculos, pois a aproximação das crianças pequenas com o espaço público cultural, inclusive, a própria chegada delas nos lugares se constituiu um grande desafio, dado que as ferramentas culturais se localizam ao centro da cidade, percebeu-se que a prioridade da organização urbana são os carros, em que pessoas adultas, que estão sempre com pressa, circulam em calçadas pequenas e o estranhamento ou encantamento frente a figura de crianças pequenas passando no centro urbano às vezes escapavam.

As pesquisas têm demonstrado, (OLIVEIRA, 20I7; BRITTO, 20I4; ULIANA, 20I4; DELAVALD, 20I3; DORNELLES, 2013) que crianças pequenas e bebês estão excluídas/os no processo de viver uma vida pública cultural, mas, isto não acontece de forma direta, mas por meio da organização da cidade e seus espaços que impedem uma movimentação livre das/os pequenas /os. Na maioria das vezes esses são hostis à sensibilidade da infância, pois é alheia e esvaziada da referência infantil e não 
compreendem suas lógicas, porque historicamente a estrutura social é pensada para as/os adultas/as. Isto acarreta no tratamento dado ao público da pequena infância, pois tudo é projetado para uma parcela da sociedade.

A cidade não acolhe as diferenças, não proporciona a mistura e sim atende apenas um padrão: homem, adulto, branco, rico e heterossexual, o centro da cidade é o centro comercial, e o que vale é o capital humano. As crianças não são produtivas, e seu valor é de consumidoras mirins ativas.

A pesquisa demonstrou que os reflexos de uma sociedade construída sem a presença da pequena infância, ocupando a vida pública, fez com que os agentes culturais não desenvolvessem um acolhimento mais digno as/os meninas/os pequenas/os, pois na maioria das vezes o atendimento era precário de contato, relação, atenção, ou, era justificado que a curadoria era somente feita a partir de crianças mais velhas do ensino fundamental, ou ainda o monitoramento era abandonado no meio, quando se não a prática era de recebê-las mediante ao controle dos corpos colocando as crianças sentadas todo o período da visita.

\section{Garimpando as minúcias}

As imersões nos espaços foram registradas por meios de fotos, vídeos, escrituras e áudio, posteriormente estes registros de campo foram organizados na documentação pedagógica que demarcavam os desdobramentos do projeto. Os registros são de autoria da professora da turma, também autora do presente artigo, e tais materiais foram levados como dados de pesquisa de mestrado finalizado em 2017.

A aproximação com a documentação colaborou num primeiro momento pela facilidade ao acesso, como mencionado a professora pesquisou sua própria prática, porém foi um grande desafio encontrar estranhamento naquilo que era tão familiar, ou seja, produzir o distanciamento necessário à produção acadêmica. Por exemplo, como levar adiante uma pesquisa que buscava indícios das experiências estéticas infantis? Quais pistas e minúcias o material poderia guardar? O que estava para além do olhar acostumado da professora/pesquisadora?

A câmera da memória colaborou no processo de garimpar as lembranças, falas, gestos e expressões das crianças que o registro físico não oferecia. E foi no processo de ir e vir nos registros e nas memórias que foram compilados os vazios, os diferenciais e os desvios que constituíram as categorias que indicavam as experiências estéticas infantis de crianças pequenas. Quanto mais os vestígios da relação das crianças com a arte ficavam aparentes, maior era minha aproximação do referencial teórico - teoria histórico-cultural e a teoria crítica-, no sentido de clarificar esses achados, e conforme os indícios e a teoria se coincidiam uma nova reescrita apresentava-se como constituinte da contribuição da pesquisa. 
A documentação colaborou na construção das categorias de análise, mas para isto foi necessário criar um inventário de todos os registros, organizados com temas relacionados ao local de visita. E a cada avanço que se tinha sobre os problemas da pesquisa foi se criando os critérios de inclusão e exclusão, mas este é um processo de vai e vem, em que a todo o momento que se desenvolve, a partir do aprofundamento do referencial teórico e a revisão da literatura, mudanças ocorrem.

\section{Visita ao Museu e o desejo de "se perder"}

Entre várias experiências de Ocupar ${ }^{5}$ os espaços culturais, a primeira visita ao Museu Prudente de Moraes $^{6}$ considerou-se um momento bem marcante. As crianças tiveram acesso aos artefatos históricos, objetos antigos, documentos, fotos que faziam parte da antiga casa presidencial como também às salas de exposições paralelas, que não devem ser tocadas. Mas o Museu em si já é uma grande obra de arte arquitetônica.

As crianças ficaram alvoroçadas, inquietas e fascinadas, da mesma forma que surpresas e alegres, conforme iam descobrindo e se deparando com o acervo e com o local. Ou seja, experiências estéticas primeiras com a arte produzem sensações e reações múltiplas nas crianças.

Figura I- Conhecendo o Museu

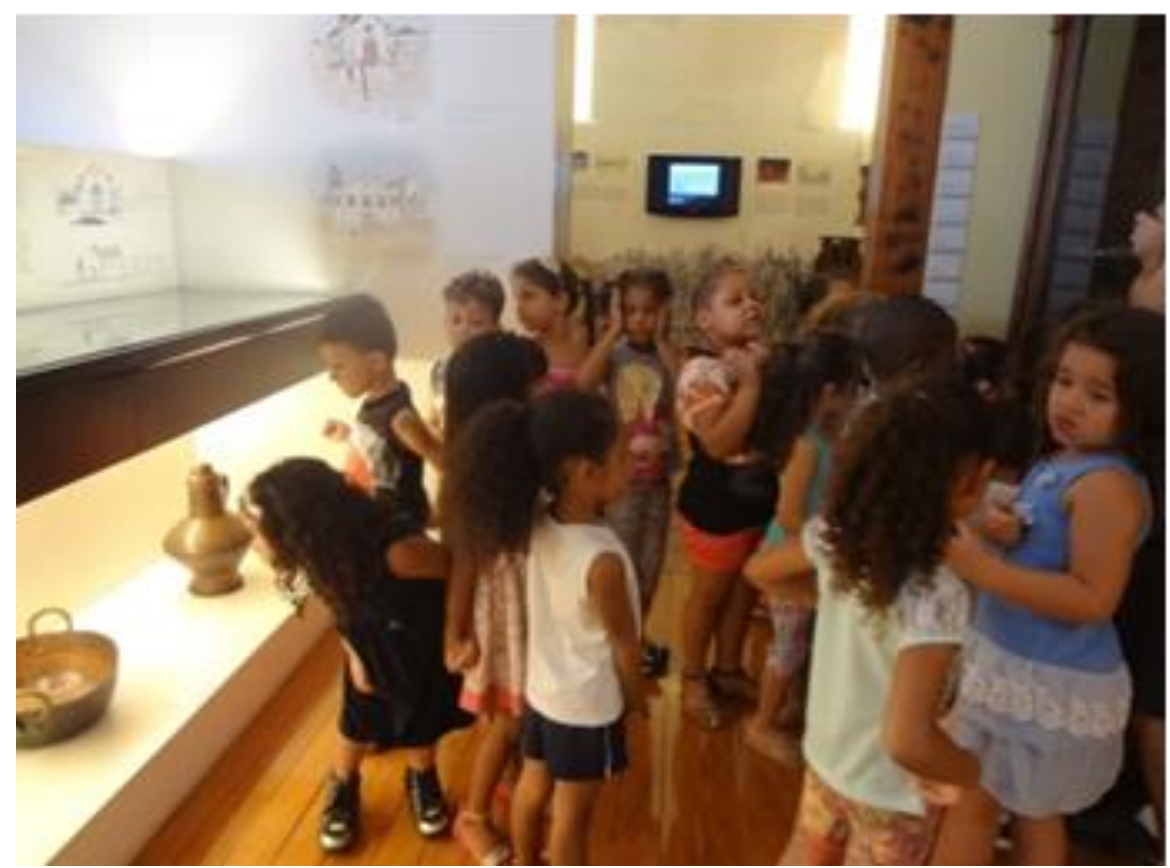

Fonte: Acervo da professora/ Detalhe Menina com as mãos no rosto, 2015.

\footnotetext{
${ }^{5}$ Foram realizadas 75 ocupações em espaços públicos por meio do projeto.

${ }^{6}$ Museu Pedagógico prudente de Morais, Piracicaba/SP.
} 
Apesar das insistências do historiador/curador do espaço em querer conduzir as crianças a uma determinada peça ou objeto, as crianças escapavam às essas lógicas condutoras e domesticadoras de olhares, elas queriam "se perder". Se perder com os olhos imaginativos, que vagavam nos "labirintos" do museu à procura dos cantos, dos móveis, das imagens, dos corredores, portas e janelas. A busca pela sensação de estar perdido nos leva ao sentimento alegórico da criança berlinense de Walter Benjamin, em Infância em Berlim por volta de 1900 (1987), que valoriza mais a capacidade de "se perder" na cidade do que saber se orientar. Admira a criança que está atenta aos arranjos dos espaços, valorizando o "pano de fundo" que compõe a cena, assim como seus objetos e as sensações que podem causar (visual, auditiva, tátil, olfativa). É outro tipo de valor estético, o infantil, porque tem interesse na busca por novas sensações que apenas o inusitado, o não saber e o que é desvendado podem proporcionar. Enquanto a experiência estética clássica e adulta procura a contemplação, o culto, a aura, a beleza viciada e canônica, as crianças nos mostram a construção de uma experiência estética infantil de sensações (OLIVEIRA, 20I7).

Figura 2- Olhando para todos os lados

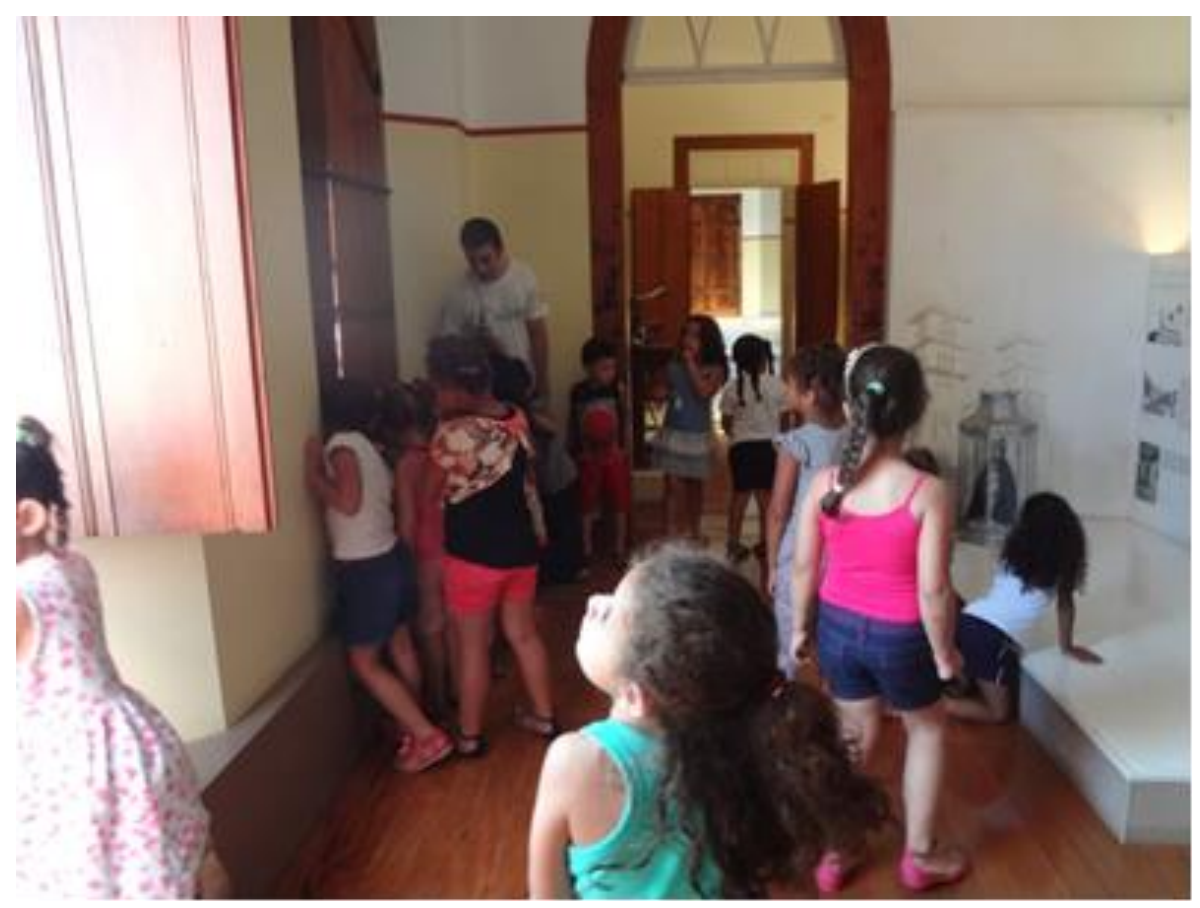

Fonte: Acervo da professora, 2015.

Neste sentido, cada detalhe presente no espaço do museu era motivo de curiosidade das crianças pequenas que eram instigadas a olhar e criar uma maneira de observar, falar e construir jeitos novos, a movimentar-se e a constituir no corpo formas para chegar até a obra/objeto/peça. Era evidente em seus corpos, gestos e falas uma mistura de sentimentos: instabilidade/coragem, mexer/não 
mexer, ansiedade/ paciência, estranhamento/afinidade. Por mais que houvesse, por parte dos adultos, um esforço para direcionar o que se deveria ver, escutar e fazer, a ligeireza e bisbilhotice das crianças, que têm na experiência do corpo a vontade de descobrir e "se perder", era dominante. Mas, em algumas situações atendiam as provocações do historiador para um determinado objeto, porém este estava condicionado à curiosidade das crianças.

A necessidade das crianças de estarem muito próximas dos artefatos do museu ficou evidente, mesmo com pedidos de afastamento o desejo de estar muito perto, de tocar, cheirar era inevitável. A recepção da arte ou mesmo da cidade e seus espaços, nos tempos atuais na formação de sujeitos modernos, se realiza pela percepção e participação, é um modo diferente de lidar com as coisas do mundo e a sua produção cultural não mais associada ao mundo burguês e individual que se aproxima da arte com recolhimento e contemplação, mas se constitui como atividade de estar em relação com a arte e a cultura (OLIVEIRA, 20I7).

No mesmo sentido, essas maneiras das crianças pequenas de lidarem com a obra de arte nos leva a fazer relação com as proposituras de Benjamin, em seu texto sobre $A$ obra de arte na época de sua reprodutibilidade técnica, 1935 (2014), no que diz respeito a percepção interativa do sujeito com arte, de trazer para compreensão o sentido amplo da estética, ou seja, da experiência estética do tato/contato, em uma dimensão corporal alicerçada no conceito da não separação corpo-mente, de uma superfície corporal que recepciona uma estética tátil que Gagnebin (2014) vai chamar de estética da tatibilidade. Esse entendimento circunda uma estética daquilo que nos toca e nos comove, que está para além do olhar e o escutar, mas se presencia fortemente no tato ${ }^{7}$, em que os sentidos não estão isolados, mas todo o corpo está exposto a diversas vivências com a arte, mesmo que a manifestação artística tenha uma exclusividade visual, como as artes visuais e plásticas, diferente da música.

Ao observar as crianças, percebemos um olhar que busca todas as direções de modo atento e minucioso, da mesma maneira com as obras e peças essa relação detalhista acontece. Algumas crianças agachadas, outras nas pontas dos pés espiando algo por cima, olhando pela janela, espreitando para além da porta tentando se antecipar e descobrir algo na próxima sala constituem as formas como essas ocupam o museu, bem como outros espaços culturais. Se para o adulto ocupar significa algo sistematizado e analítico para a criança é "se perder", é uma experiência de desvios e divagação, pois as crianças tinham esse desafio de tentar alcançar e conhecer essas produções. $E$ isto requer deslocamento e contorno do que está padronizado e esperado, às vezes é estar pelas bordas ou por dentro e às vezes também é fugindo da rota para fazer novos caminhos.

\footnotetext{
${ }^{7}$ Ver em Gagnebin em: “De um a estética da visibilidade a uma estética da tatibilidade”, 2014.
} 
O Museu é lugar de brincadeira?

Outra forma produzida pelas crianças para lidar com os espaços e as obras era brincar. $O$ ato de brincar demanda imaginar, criar e inventar, neste sentido, "conversar" com uma escultura, criar uma narrativa em relação à imagem de um quadro, imitar uma estátua, inventar algo sobre determinada foto ou objeto e a própria emoção vivenciada durante exploração e experimentação do espaço é uma forma peculiar das crianças, e com isto uma forma infantil, de constituir relação e lidar com a obra de arte e o espaço cultural. Essa relação brincante e de desvio da experiência estética infantil tem no campo sensorial a oportunidade de explorar diferentes sensações.

\section{A experiência brincante frente à arte: "Foge Chapeuzinho, foge"!'8}

As formas como as crianças pequenas se apropriam da cultura se constitui como um processo permeado de sentimentos, emoções e imaginação. Tal envolvimento também é possível perceber com as histórias, porque é como se tivessem dentro delas interagindo com os acontecimentos, vivendo junto aos personagens as aventuras.

As crianças tiveram a oportunidade de assistir uma peça de dança no teatro da cidade, e aconteceu a seguinte situação:

Sobre Chapeuzinho Vermelho

(...) num determinado momento a companhia de dança apresentou um balé sobre "Chapeuzinho Vermelho", que chamou muito a atenção das crianças:

Duda se encolheu na poltrona brincando que estava com medo do lobo que apareceu durante a coreografia; as crianças entre elas diziam baixinho: "foge chapeuzinho, foge"; Guilherme a todo o momento fica em pé apontando para o lobo escondido, tentando mostrar, alertar a Chapeuzinho para sair de onde estava.

(...) Na hora de ir embora as crianças saíram dançando pelo pátio, frente ao teatro. (registro escrito da professora, 2015)

\footnotetext{
${ }^{8}$ Todos os episódios apresentados estão presentes no texto de dissertação como dados da pesquisa.

${ }^{9}$ Recorte extraído do caderno de registro. Balé Chapeuzinho Vermelho é um trecho do espetáculo de balé $\mathrm{A}$ Bela Adormecida, de Marius Petipa, com música de Tchaikovsky, inspirado nos contos de Perrault.
} 
Figura 3: Chapeuzinho Vermelho

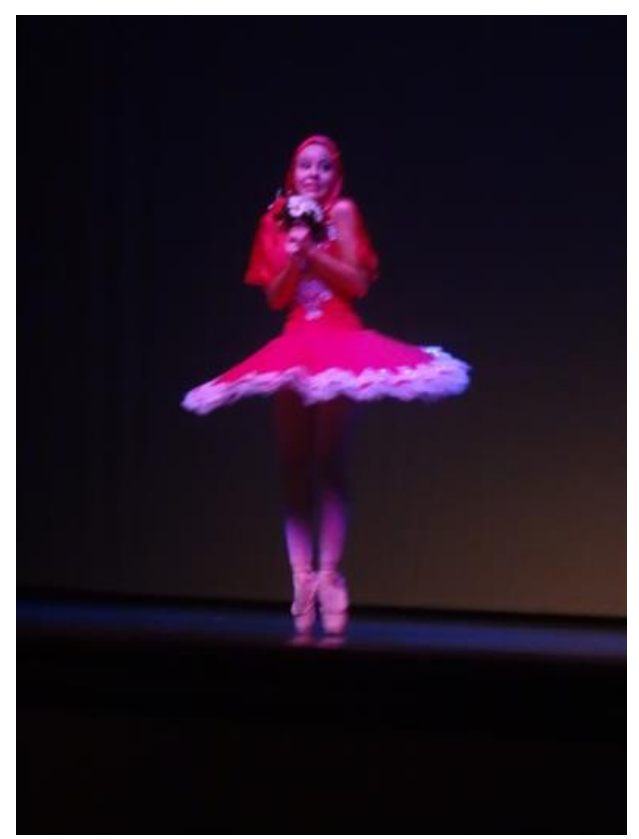

Fonte: acervo da professora, 2015.

O envolvimento emocional delas com a história dançada "Chapeuzinho Vermelho", um clássico já conhecido pelo grupo, fez com que elas reagissem frente ao enredo e criassem uma relação participativa, como um "espelho tátil".

As crianças ficaram aflitas e tensas ao verem a movimentação do lobo mal no palco perseguindo a Chapeuzinho, pois são imagens vivas e estéticas; a situação encenada de perigo e a representação de ameaça causa uma agitação na cena que empolga as/os pequenas/os. Algumas crianças ficavam inquietas, movimentavam-se na cadeira, levantavam e também torciam pela a personagem da Chapeuzinho, encorajando-a a fugir, e por estarem envolvidas afetivamente com a história, mesmo sabendo que era um faz-de-conta, estavam tomadas por um sentimento verdadeiro vivenciado naquele momento, de tal maneira que, ao alertar ou torcer para ela escapar, evidenciaram sua participação e envolvimento no/com o enredo dos acontecimentos. Isto é, os sentimentos das crianças eram exteriorizados.

As paixões e os destinos dos heróis inventados, sua alegria e desgraça perturbamnos, inquietam-nos e contagiam-nos, apesar de estarmos diante de acontecimentos inverídicos, de invenções da fantasia. Isso ocorre porque as emoções provocadas pelas imagens artísticas fantásticas das páginas de um livro ou do palco de teatro são completamente reais e vividas por nós de verdade, franca e profundamente (VIGOTSKI,2009, p. 29).

Toda essa vivência de "espectadoras" da apresentação de dança provocou nas crianças sentimento de entusiasmo, torcida, vibração. Mas, também de atenção aos detalhes e minúcias presentes que estavam sendo exibido, cada salto, giro, passos gerava expressões nas crianças, aplausos, surpresas, risos, espanto, admiração. 
O que se percebe é o interesse de reproduzir e de brincar sobre o que viram, e contagiadas pelo espetáculo de dança ao saírem do teatro criaram uma brincadeira de dançar fazendo movimentos que imitassem as coreografias assistidas.

Imaginar e brincar de ser bailarina ou bailarino, de assumir o papeis dos outros (do jeito próprio das crianças), criando uma brincadeira a partir dessa experiência artística é a resposta dada pelas crianças diante do que viveram. Consideramos como um reflexo estético, pois pra criança a fantasia não permanece muito tempo no campo do devaneio, ela necessita encarnar em ações vivas as impressões que $o$ ambiente apresenta.

Mas também é a experiência do o "mais uma vez", de repetir para se assemelhar, viver o prazer do retorno, não como cópia, mas transformando-se e transformando esse conhecimento.

A atividade de imitar das crianças é marcada pelo desejo do fazer também, do "agora é a minha vez", "minha vez de experimentar”. Brincar/ jogar é o meio de materializar essa vontade, de produzir semelhanças, pois é na brincadeira que as tentativas sobre o que querem imitar vão sendo criadas, e com isto o novo e o diferente vão sendo construídos.

Se a experiência de aprender o mundo pela criança é pelo brincar e pela tendência da repetição, que nós educadoras/es continuemos a alimentá-la, sem desbotamento. Nesse sentido, na perspectiva de Benjamin(20l4), a estética se enriquece com o espaço de jogo e se destaca como lugar de reservas inesgotáveis, não apenas pelo caminho da repetição, mas porque também se constitui como espaço de desconstrução e reconstrução do mundo.

A imitação, sob o prisma da mímesis criadora, mostra-se como caminho para as crianças se aproximarem da arte; e o estudo mostrou na análise feita a partir do registro fotográfico de Bianca (5 anos) tomada pelo contato com a obra, na ação de vivenciar essa relação mimética da arte. A ação mimética do brincar, como na arte, envolve a (re) significação das coisas da vida e quando as crianças atribuem novos sentidos a obra de arte por meio das brincadeiras estão contribuindo na (re) atualização no campo da experiência estética. 
Figura 4: Mímesis Criadora

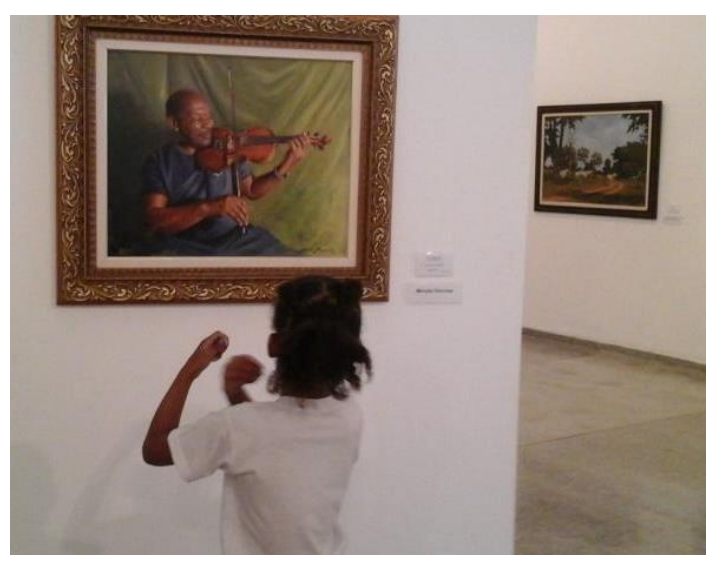

Fonte: acervo da professora, 2015.

Diante de uma pintura de um violinista, ela começou a se movimentar, tocando um violino imaginário, numa mímica, ao mesmo tempo em que com a boca fazia um som e mexia o corpo no ritmo deste som ficando ali por algum tempo envolvida com a movimentação que havia criado. (Registro da professora, 2015).

Entendemos que esse sentido imitativo atribuído por Bianca não é uma cópia idêntica do quadro, mas, está atravessada por uma criativa elaboração e expressão de movimentos corpóreos (som musical com a boca, a movimentação com o corpo balançando no ritmo da produção de seu som, movimento de tocar um violino imaginário), é uma reação ao que a pintura provoca demarcada por um processo de invenção e de caráter sincrético, uma integração dos diferentes tipos de arte.

As crianças produzem modos peculiares e originais para se aproximarem da arte, e esses modos expressam as características da experiência estética infantil, e a maneira de se desenvolver pela sensibilidade, e por a experiência não ter um padrão, uma forma definida, e sim uma reação ao encantamento a novidade que a obra se apresenta diante do espectador. Contudo, a criança pequena quanto espectadora é atravessada pela sensação mudando significativamente o estado anterior, inicial, e essa mudança intensa das crianças produz uma qualidade de experiência estética muito particular, peculiar e especial.

O projeto de ocupação possibilitou ao grupo de crianças um processo de transformação de suas posturas, principalmente como desdobramentos decorrentes da aproximação contínua delas com a arte, e outras expressões foram se mostrando presentes nas ações das crianças. Pois, conforme as crianças iam se constituindo mais autônomas nos espaços culturais suas circulações se tornavam menos restritivas, e o ato de especular, investigar, bisbilhotar, ou seja, suas curiosidades transfiguravam-se mais evidentes e ampliadas. 


\section{Considerações finais}

Olhar para a produção da experiência estética infantil de crianças pequenas é inspirador e poético, suas formas e maneiras de lidarem com os espaços e a obra de arte encanta os olhos de quem as observa.

A pesquisa por meio do garimpo das minúcias infantis possibilitou coletar uma diversidade de categorias que sinalizam os modos como às crianças pequenas constituem as experiências estéticas infantis. Esses modos são posturas peculiares frente a arte, pois entende-se que as/os pequenas/os produzem uma maneira singular de vivenciar suas experiências, diferente da pessoa mais velha que está acarretada pelas lógicas dos cânones artísticos.

Aprendemos que a experiências do brincar, que é inventivo, imaginativo, interativo promove a apropriação da arte pelas crianças, tendo na mímesis criadora o intermédio que possibilita a participantes delas no acesso às linguagens das artes, identificando como as coisas são, transformandoas e se transformando, num processo expressivo de criação.

As reflexões sobre o despreparo e o desrespeito dos espaços públicos culturais e artísticos, por meio dos seus agentes, no atendimento às crianças pequenas e bebês são impactos de uma sociedade que foi se desenvolvendo a partir de prioridades outras que excluíram essas do processo de se envolverem com a vida social na cidade, e o direito à cidade. Tanto a organização da cidade, a organização dos espaços culturais e seus profissionais não sabem acolher as demandas infantis e desconhecem totalmente o que constitui o saber infantil e a criança. Os/as profissionais que faziam o atendimento nos espaços, quando não ignoravam a presença das crianças buscavam nelas uma postura que não condizem com suas idades, numa abordagem escolarizante e canônica de apresentar as obras.

Mas, os sonhos infantis nos espaços públicos incomodam, e este incômodo nos alerta para pensar sobre políticas públicas culturais às crianças incorporadas ao direito à cidade, o acesso ao conhecimento, o direito á arte e sua formação estética. A experiência com o projeto de Ocupação demonstrou que crianças pequenas são capazes de produzir suas próprias experiências. São talentosas no processo de criar e atribuir sentido à obra e transformando a arte. Construíram-se brincantes frente à cultura à qual pertence e desviante também, porque elabora novas rotas para explorar com maior dignidade.

A experiência estética infantil foi valorizada por meio desse projeto de Ocupação, pois a concepção de criança e infância que está presente é aquela que a considera como parte da cultura atuando e não como um eterno vir a ser. A criança tem o seu modo de ser apreciadora da arte, $e$ dessa forma é participante, dialogando, questionando, produzindo narrativas, explorando e descobrindo esse mundo. 


\section{Referências}

AITKEN, S. Do apagamento à revolução: o direito da criança à cidadania/direito à cidade. Educação e Sociedade, Campinas, v. 35, n. 128, p. 629-982, jul.-set., 2014. Disponível em: https://www.scielo.br/pdf/es/v35n I 28/0 I0I-7330-es-35-128-00675.pdf. Acesso em: mai. 202I.

BENJAMIN, W. Infância em Berlim por volta de 1900. In: BENJAMIN, W. Obras escolhidas II: Rua de Mão Única. São Paulo: Brasiliense, 1987.

BENJAMIN, W. A obra de arte na época de sua reprodutibilidade técnica. Tradução e notas de Francisco de Ambrosis Pinheiro Machado. Porto Alegre: Zourk, 2014.

BRASIL. Diretrizes Curriculares Nacionais Gerais da Educação Básica. Ministério da Educação. Secretaria de Educação Básica. Câmara Nacional de Educação Básica Diretoria de Currículos de Educação Integral. Brasília: MEC, SEB, DICEI, 2013. Disponível em: http://portal.mec.gov.br/index.php?option=com_docman\&view=download\&alias=13448-diretrizescuriculares-nacionais-2013-pdf. Acesso em: mai. de 202I.

BRITTO, L. Oficinas de arte contemporânea para crianças de pré-escola: a experiência estética e o lúdico na infância. 2014. Dissertação (Mestrado em Artes Visuais) - Universidade Federal de Pelotas, Pelotas, 2014. Disponível em: http://repositorio.ufpel.edu.br/handle/ri/2768. Acesso em: mai. 2021 .

CRUZ, M. Modos de Participação do adulto em processo de produção de significações: apontamentos para a investigação da formação de professores de educação infantil. In: IX Congresso estadual paulista sobre formação de educadores, 2007, São Paulo. Anais [...] São Paulo: UNESP, 2007. p. 23I-238. Disponível em: file:///C:/Users/Usuario/Downloads/9eixo\%20(4).pdf. Acesso em: mai. 2021.

DELAVALD, C. C. A infância no encontro com a arte contemporânea: potencialidades para educação. 2013. Dissertação (Mestrado em Educação) - Universidade Federal do Rio Grande do Sul, Porto Alegre, 2013. Disponível em: http://www.lume.ufrgs.br/bitstream/handle/I0183/7/274/000879/05.pdf?sequence=I> Acesso em: mai. 2021.

DORNELLES, A. E. Crianças em espaços expositivos: abrimos a porta do Gigante. 2013. Dissertação (Mestrado em Educação) - Universidade Federal do Rio Grande do Sul, Porto Alegre, 2013.

Disponível

em: https://www.lume.ufrgs.br/bitstream/handle/I0183/83304/000906097.pdf?sequence=I. Acesso em: mai. 2021.

EAGLETON, T. A ideologia da estética. Tradução de Mauro Sá Rego Costa. Rio de Janeiro: Zahar, 1993.

GAGNEBIN, J. M. De uma estética da visibilidade a uma estética da tatibilidade. In: GAGNEBIN, J.M. Limiar, aura e rememoração: ensaios sobre Walter Benjamin. São Paulo: Editora 34, 2014. p. 155175.

Instituto Tomie Ohtake “2014". Prêmio Territórios. Disponível em: https://www.institutotomieohtake.org.br/premios/territorios-educativos. Acesso em: jan. 202I.

LOPES. J. J.M.; VASCONCELLOS. T. Geografia da infância: reflexões sobre uma área de pesquisa. Juiz de Fora: Feme, 2005. 
OLIVEIRA, F. F. Produção de Sentido e Experiência Estética na Educação Infantil. 2017. Dissertação (Mestrado em Educação) - Universidade Metodista de Piracicaba, Piracicaba, 2017. Disponível em: http://iepapp.unimep.br/biblioteca_digital/pdfs/docs/I5I22017_I4I559_fernandaferreiradeoliveira_ok. pdf. Acesso em: mai. 2021.

Portal Aprendiz "2020". Cidade Educadora. Disponível em: https://portal.aprendiz.uol.com.br/2020/06/I6/territorios-de-sao-paulo-se-mobilizam-para-o-festivalocupa-cidadel. Acesso em: jan. 202I.

ULIANA, D. da P. P. Experiência Sensível na Educação Infantil: Um encontro com a arte. 2014. Dissertação (Mestrado em Educação) - Universidade Federal do Espírito Santo, Espírito Santo, 2014. Disponível em: http://repositorio.ufes.br/handle/I0/I340. Acesso em: mai. 202 I.

VIGOTSKI, L. S. Imaginação e Criação na infância: ensaio psicológico. Tradução Zoia Prestes. São Paulo: Ática, 2009.

Recebido em: 15 de março de 2021.

Versão corrigida recebida em: 23 de maio de 2021 .

Aceito em: 25 de maio de 2021 .

Publicado online em: 21 de agosto de 2021 . 